\title{
A molecular dynamics simulation of energetics and diffusion of point defects in a Au-Ag alloy
}

\author{
RU-SONG LI*®, FEI LI, DU-QIANG XIN, JI-JUN LUO, SAIFEI CHEN and YU ZHANG \\ Xijing University, Xijing Road, Xi'an 710123, People's Republic of China \\ *Author for correspondence (20170213@xijing.edu.cn)
}

MS received 28 August 2018; accepted 12 November 2018; published online 16 April 2019

\begin{abstract}
For revealing an aging mechanism for self-irradiation in a Pu-Ga alloy, we carried out a molecular dynamics (MD) simulation on a substitutional material, i.e., Au-Ag alloy. In this work, we estimate physical and microscopic properties of the $\mathrm{Au}-\mathrm{Ag}$ alloy containing various point defects using a MD method, in particular, formation energy for point defects, migration energy for point defects diffusion into interstitial sites, and diffusion coefficient for the Au-Ag alloy containing point defects, such as vacancy, He atom and He-vacancy (He-V) cluster. The results indicate that volumetric heat capacity and linear expansion coefficient would decrease due to the various point defects, and He atom has the most remarkable influence on the physical properties of the $\mathrm{Au}-\mathrm{Ag}$ alloy for point defects considered in this work. The formation energy of $\mathrm{Au}$ and Ag self-interstitial atom indicates that Octa1 is the most stable site, and structural stability of octahedral (Octa) interstitial sites for the He atom obeys Octa1 $>$ Octa2 $>$ Octa4 $>$ Octa3. For the $\mathrm{He}_{n} \mathrm{~V}_{m}$ cluster, the formation energy of the defect structure is most stable at $n=m$. The diffusion coefficient of the He- $\mathrm{V}$ cluster is relatively smaller, showing that vacancy defects would further decrease atomic diffusion. An influence of various point defects on the diffusion velocity in the $\mathrm{Au}-\mathrm{Ag}$ alloy obeys the He-V cluster $>\mathrm{He}>$ vacancy $>\mathrm{Ag}>\mathrm{Au}$.
\end{abstract}

Keywords. Radiation damage; point defects; formation energy; migration energy; molecular dynamics.

\section{Introduction}

Over past few years, we have witnessed dramatic progress in nucleation and growth mechanisms for He behaviour in $\mathrm{Pu}$-based materials, in particular, pure $\delta$ phase $\mathrm{Pu}$ and $\mathrm{Pu}-$ $\mathrm{Ga}$ alloys [1-10]. Being a radioactive nuclide, $\mathrm{Pu} \alpha$ decay would produce various defects, such as He interstitial atom, self-interstitial atom (SIA) and vacancy, resulting in collision displacement cascade, and disrupt physical, chemical and mechanical properties of the Pu-based system. Therefore, the self-irradiation effect, in particular, behaviour of $\mathrm{He}$ defects, would be useful for revealing aging mechanisms in Pu metal. However, we have not yet completely understood the selfirradiation effect in Pu material, in particular, aggregation of He atom, nucleation and growth of a He-vacancy (HeV) cluster and/or He bubble, which still demands for further investigation [10]. Recently, many research groups [11-14] have reported on collision displacement cascade induced by self-irradiation due to $\alpha$ decay in Pu-based materials using a multi-scale simulation technique, e.g., first principles, molecular dynamics (MD) and kinetic Monte Carlo. In fact, experimental work on the behaviour and properties of $\mathrm{He}$ atom in $\delta-\mathrm{Pu}$ is very difficult to perform due to its chemical activity, toxicity, radioactivity and instability of a lattice structure [11-14]; therefore, experimental observation and/or numerical simulation on a substitution material for the $\mathrm{Pu}-\mathrm{Ga}$ alloy might be a feasible approach. In principle, two important material properties for studying radiation damage in irradiated materials due to self-irradiation are crystal structure and mass density. Different distributions and types of radiation-induced defects would be produced for different crystal structures with different crystal structures or compositions. On the other hand, mass density influences the distance that an energetic particle transports through a material due to an interaction cross-section between the incident atom and host atom, and thus, affects the concentration of radiation defects [15]. For these reasons, we take the $\mathrm{Au}-\mathrm{Ag}$ alloy (face-centred cubic structure) as an opposite surrogate for the $\mathrm{Pu}-\mathrm{Ga}$ alloy (fcc structure). In this respect, physical properties, point defect properties and $\mathrm{He}$ behaviour in the Au-Ag alloy might be useful to understand the $\mathrm{He}$ behaviour in the $\mathrm{Pu}-\mathrm{Ga}$ alloy. Stevens et al [15] have used transmission electron microscopy (TEM) to investigate the nucleation and growth of He defects in the $\mathrm{Au}-\mathrm{Ag}$ alloy, and found that He bubbles are not homogeneously distributed across the crystal lattice, and nucleation of $\mathrm{He}$ bubbles might not be related to He irradiation in the $\mathrm{Au}-\mathrm{Ag}$ alloy. For $\mathrm{He}$ behaviour in the $\mathrm{Au}-\mathrm{Ag}$ alloy, Thomé and Grynszpan [16] have investigated radiation damage in a $\mathrm{He}$ implanted Au-based alloy $\left(\mathrm{Au}_{3} \mathrm{Ag}_{2}\right)$ using a positron annihilation spectrum (PAS) technique. The results indicate that a fundamental reason for the degradation of 
the $\mathrm{Au}_{3} \mathrm{Ag}_{2}$ alloy is an increase in pressure resulting from nucleation and growth of He bubbles. Zhu [17] has studied typical point defects in the $\mathrm{Au}-\mathrm{Ag}$ alloy, such as $\mathrm{He}$ atom interstitial, vacancy and its cluster, from first principles calculations using density functional theory (DFT), and evaluated formation energies for the $\mathrm{He}$ atom in individual defect sites. The results show that relative stability of point defects and formation energies of the $\mathrm{He}$ atom in the $\mathrm{Au}-\mathrm{Ag}$ alloy are in close relationship with an atomic configuration of the host atom in the vicinity of the defect site and mass density. Metallurgically, a fcc $\delta$ phase Ga $1.0 \mathrm{wt} . \% \mathrm{Pu}-\mathrm{Ga}$ alloy has a mass-density of $15.8 \mathrm{~g} \mathrm{~cm}^{-3}$. The $\mathrm{Au}-\mathrm{Ag}$ system is viewed as a suitable surrogate for the $\mathrm{Pu}-\mathrm{Ga}$ alloy in terms of its complete miscibility, its fcc crystal structure and mass density of the $\mathrm{Au}-\mathrm{Ag}$ alloy composed of $60 \mathrm{wt} . \% \mathrm{Au}$ and 40 wt.\% Ag. In this work, therefore, we choose a fcc Au$\mathrm{Ag}$ alloy (60 wt. $\% \mathrm{Au}+40 \mathrm{wt} . \% \mathrm{Ag})$ as a candidate for the $\delta$ phase $\mathrm{Pu}-\mathrm{Ga}$ alloy, thus the atomic ratio of $\mathrm{Au} / \mathrm{Ag}$ is about 9:11.

To our knowledge, some research groups have adopted the first principles method within the framework of DFT to study the physical properties of the Au-Ag alloy and microscopic behaviour of He defects [17], however, seldom reports have paid attention on MD simulation for $\mathrm{He}$ behaviour in the $\mathrm{Au}-\mathrm{Ag}$ alloy. In this work, we will adopt the MD method to analyse the physical properties and $\mathrm{He}$ behaviour in the $\mathrm{Au}-\mathrm{Ag}$ alloy using an embedded atom method (EAM) potential, which might shed light on understanding the He point defects in the $\mathrm{Au}-\mathrm{Ag}$ alloy. This paper is organized as follows. In section 2, we present a structure model and computational details. Then, we will analyse the influence of point defects on the physical properties of the $\mathrm{Au}-\mathrm{Ag}$ alloy in section 3. In section 4, we will evaluate the formation energies for single $\mathrm{Au}$ and $\mathrm{Ag}$ atoms, $\mathrm{He}$ atom in octahedral (Octa) and tetrahedral (Tetra) interstitial sites and $\mathrm{He}_{n} \mathrm{~V}_{m}$ (V represents vacancy) cluster. Next, we will discuss migration energies for $\mathrm{Au}, \mathrm{Ag}$ and $\mathrm{He}$ atom diffusion into interstitial sites in section 5. In section 6 , we will evaluate the effective diffusion coefficient for various point defects using the MD method, and analyse the influence of these defects on the effective diffusion coefficient. Finally, we will give summary remark and outlook in section 7 .

\section{Computational details}

\subsection{Structure model}

For the simulation model of an $\mathrm{Au}-\mathrm{Ag}$ alloy, we construct a $5 a_{0} \times 1 a_{0} \times 1 a_{0}$ supercell (20 Ag atoms, $a_{0}$ represents the lattice constant of fcc Ag metal), and substitute partial $\mathrm{Ag}$ atoms by $\mathrm{Au}$ atoms to obtain an atomic ratio of $\mathrm{Au} / \mathrm{Ag}$ as 9:11. Then, we expand this supercell to a periodic $20 a_{0} \times$ $20 a_{0} \times 10 a_{0}$ simulation cell (including 16,000 atoms in total), as shown in figure 1 .

For a monatomic fcc crystal, interstitial defects include only two types, i.e., Tetra and Octa interstitial sites due to equivalence of host atoms [18]. However, $\mathrm{Au}$ atom is not equivalent to $\mathrm{Ag}$ atom in the $\mathrm{Au}-\mathrm{Ag}$ alloy, hence, interstitial sites for $\mathrm{Au}$ and $\mathrm{Ag}$ atoms, respectively. According to the atom type and number of the first nearest neighbours (1NN) for interstitial sites, four Octa and two Tetra interstitial sites are shown in figure 2 , and the atom type and number are listed in table 1 .

\subsection{Methodology}

All MD simulations in this work are carried out within the classical MD code in the LAMMPS software package. Periodic boundary conditions are adopted. For the formation energy of the interstitial atom in the $\mathrm{Au}-\mathrm{Ag}$ alloy, an annealing MD method is used to completely relax the $\mathrm{Au}-\mathrm{Ag}$ alloy including interstitial atom, and obtain an atomic configuration with the minimum energy; computational details for energetics and diffusion properties are presented below.

In $\mathrm{MD}$ simulations, we have used $\mathrm{Au}, \mathrm{Ag}$ and $\mathrm{Au}-\mathrm{Ag}$ embedded atom model (EAM) potentials of Zhou et al $[19,20]$ and $\mathrm{He}-\mathrm{He}$ potential of Valone et al [21]. For $\mathrm{Au}-\mathrm{He}$ and $\mathrm{Ag}-$ $\mathrm{He}$ interatomic potentials, we perform first principles calculations on hypothetical $\mathrm{Au}_{3} \mathrm{He}$ and $\mathrm{Ag}_{3} \mathrm{He}$ crystals $\left(\mathrm{L}_{2}\right.$ lattice structure) within the space group of $P m \overline{3} m$, and fit to a revised form of the universal equation of state of Rose et al $[1,22]$.

$$
\begin{aligned}
E(R) & =-E_{\mathrm{c}}\left(1+a^{*}+\mu a^{* 3} \frac{r_{\mathrm{e}}}{R}\right) \mathrm{e}^{-a^{*},} \\
a^{*} & =\alpha\left(\frac{R}{r_{\mathrm{e}}}-1\right),
\end{aligned}
$$

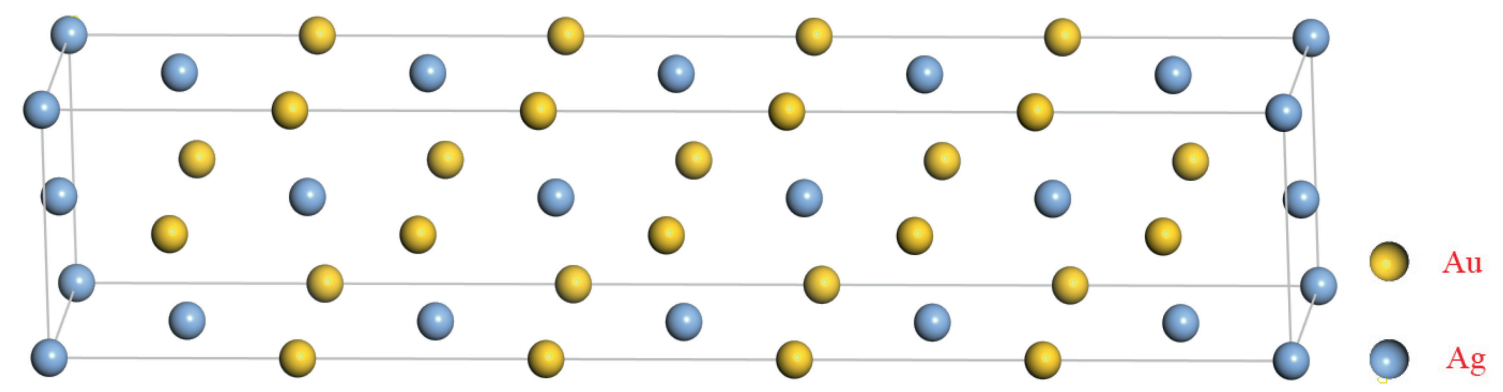

Figure 1. A simulation model for the $\mathrm{Au}-\mathrm{Ag}$ alloy. Yellow and blue spheres represent $\mathrm{Au}$ and $\mathrm{Ag}$ atoms, respectively. 


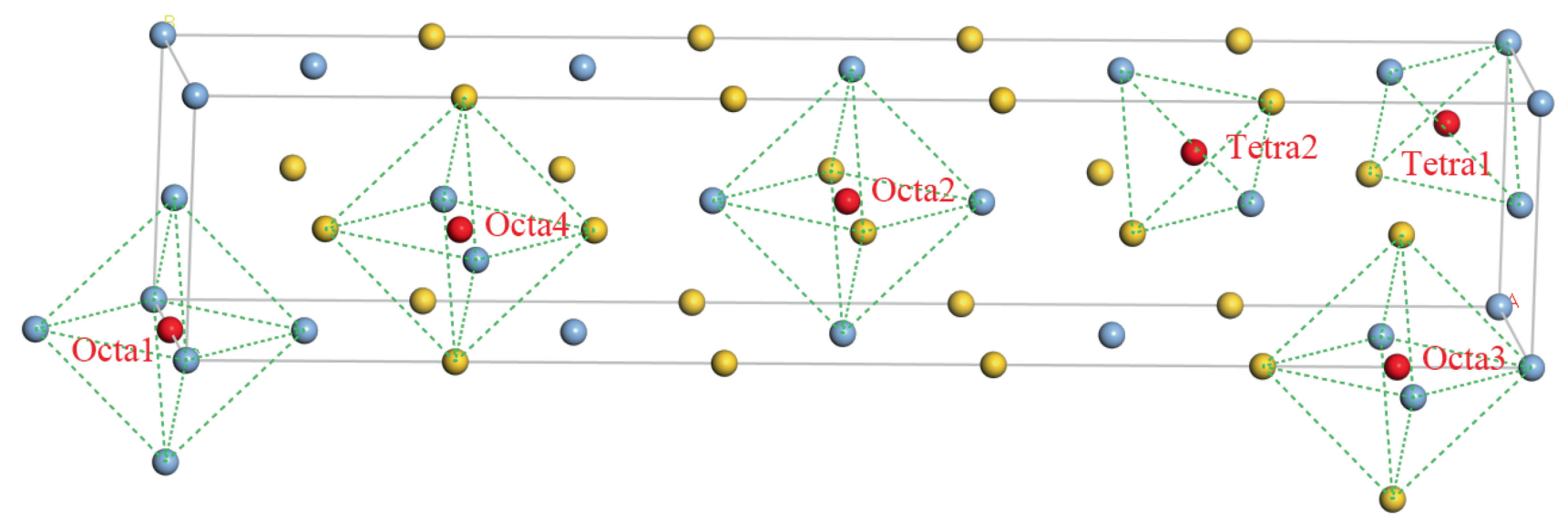

Figure 2. Atomic configuration for four Octa and two Tetra interstitial sites in the Au-Ag alloy. Yellow, blue and red spheres represent $\mathrm{Au}, \mathrm{Ag}$ and $\mathrm{He} / \mathrm{SIA}$ atoms, respectively.

Table 1. Number of the first nearest neighbour (1NN) for interstitial sites in the $\mathrm{Au}-\mathrm{Ag}$ alloy.

\begin{tabular}{lccccccc}
\hline Interstitial site & Octa1 & Octa2 & Octa3 & Octa4 & Tetra1 & Tetra2 \\
\hline Number of Au atom & 0 & 2 & 3 & 4 & 1 & 2 \\
Number of Ag atom & 6 & 4 & 3 & 2 & 3 & 2 \\
\hline
\end{tabular}

$$
\alpha^{2}=\frac{9 \Omega B}{E_{\mathrm{c}}},
$$

where $E_{\mathrm{c}}, r_{\mathrm{e}}, \Omega$ and $B$ are the cohesive energy, nearestneighbour distance, atomic volume and bulk modulus at the equilibrium reference structure, respectively. $\mu$ is a dimensionless quantity related to the pressure derivative of the bulk modulus.

First principles calculations in this work are implemented by DFT using an all-electron full potential linearized augmented plane wave (FP-LAPW) method within the framework of the WIEN2 K code [23-25]. The exchange-correlation energies are approximated with the Perdew-BurkeErnzerhof (PBE) [26] form of generalized gradient approximation (GGA). The maximum $l$ values for partial waves used inside muffin-tin (MT) spheres are up to $l_{\max }=10$. The cutoff parameter is $R_{\mathrm{mt}} \times K_{\max }=9$. In an interstitial region, the charge density and the potential are expanded as a Fourier series with wave vectors up to $G_{\max }=12$ a.u. $^{-1}$. The MT radius values are set to be 2.00, 2.00 and 1.60 Bohr for $\mathrm{Au}, \mathrm{Ag}$ and $\mathrm{He}$ atoms, respectively. The optimized lattice constants for $\mathrm{Au}_{3} \mathrm{He}$ and $\mathrm{Ag}_{3} \mathrm{He}$ are 4.0671019 and $4.1256438 \AA$. The modified EAM (MEAM) potential parameters for $\mathrm{Au}-\mathrm{He}$ and Ag-He crystals are shown in table 2.

For the formation energies of interstitial atoms in the $\mathrm{Au}-$ $\mathrm{Ag}$ alloy, MD simulations are carried out using annealing MD under periodic boundary conditions. For the initial configuration containing 16,000 atoms, temperature slowly increases
Table 2. MEAM potential parameters for $\mathrm{Au}-\mathrm{He}$ and $\mathrm{Ag}-\mathrm{He}$ interatomic potentials.

\begin{tabular}{|c|c|c|c|}
\hline Parameter & $\mathrm{Au}-\mathrm{He}$ & $\mathrm{Ag}-\mathrm{He}$ & Meaning \\
\hline$E_{\mathrm{c}}(\mathrm{eV})$ & 0.07752 & 0.11041 & Cohesive energy \\
\hline$R_{0}(\AA)$ & 2.87629 & 2.91768 & $\begin{array}{l}\text { Nearest-neighbour } \\
\text { distance }\end{array}$ \\
\hline$\alpha$ (dimensionless) & 34.4269 & 21.99064 & $\begin{array}{l}\text { Definition in } \\
\text { equation (3) }\end{array}$ \\
\hline$\delta$ (dimensionless) & 6.06854 & 5.95779 & $\begin{array}{l}\text { Definition in } \\
\text { equation (1) }\end{array}$ \\
\hline$B(\mathrm{GPa})$ & 97.23950 & 54.13636 & Bulk modulus \\
\hline$Z$ (dimensionless) & 12 & 12 & $\begin{array}{l}\text { Number of } \\
\text { nearest- } \\
\text { neighbour }\end{array}$ \\
\hline
\end{tabular}

The parameters are for a fit to the Rose curve.

from 0.0001 to $300 \mathrm{~K}$ during 80,000 steps within the NVT ensemble; time step is set to $5.0 \mathrm{fs}$. The total simulation time of $400 \mathrm{ps}(80,000$ steps) is enough for the formation energies of interstitial atoms in the $\mathrm{Au}-\mathrm{Ag}$ alloy though it might seem inadequate for conventional MD simulation. For the $\mathrm{He}$ atom or SIA, they are added to the interstitial site when the temperature reaches $300 \mathrm{~K}$. Then, the system is completely relaxed through isothermal MD simulation during 5000 steps within the NPT ensemble $(P=1.0 \mathrm{~atm})$. Next, the system is slowly cooled to $0.0001 \mathrm{~K}$ during 80,000 steps within the NVT ensemble where the volume $V$ is defined as the average value of the above NPT equilibriation. Finally, we will obtain an energetically optimal configuration containing interstitial atom.

For the formation energy of the $\mathrm{He}_{n} \mathrm{~V}_{m}$ cluster ( $\mathrm{V}$ represents vacancy), we delete the metallic atom in the centre site of the simulated cell to model a mono-vacancy defect, and then, fully relax this system to reach a new energy equilibrium 

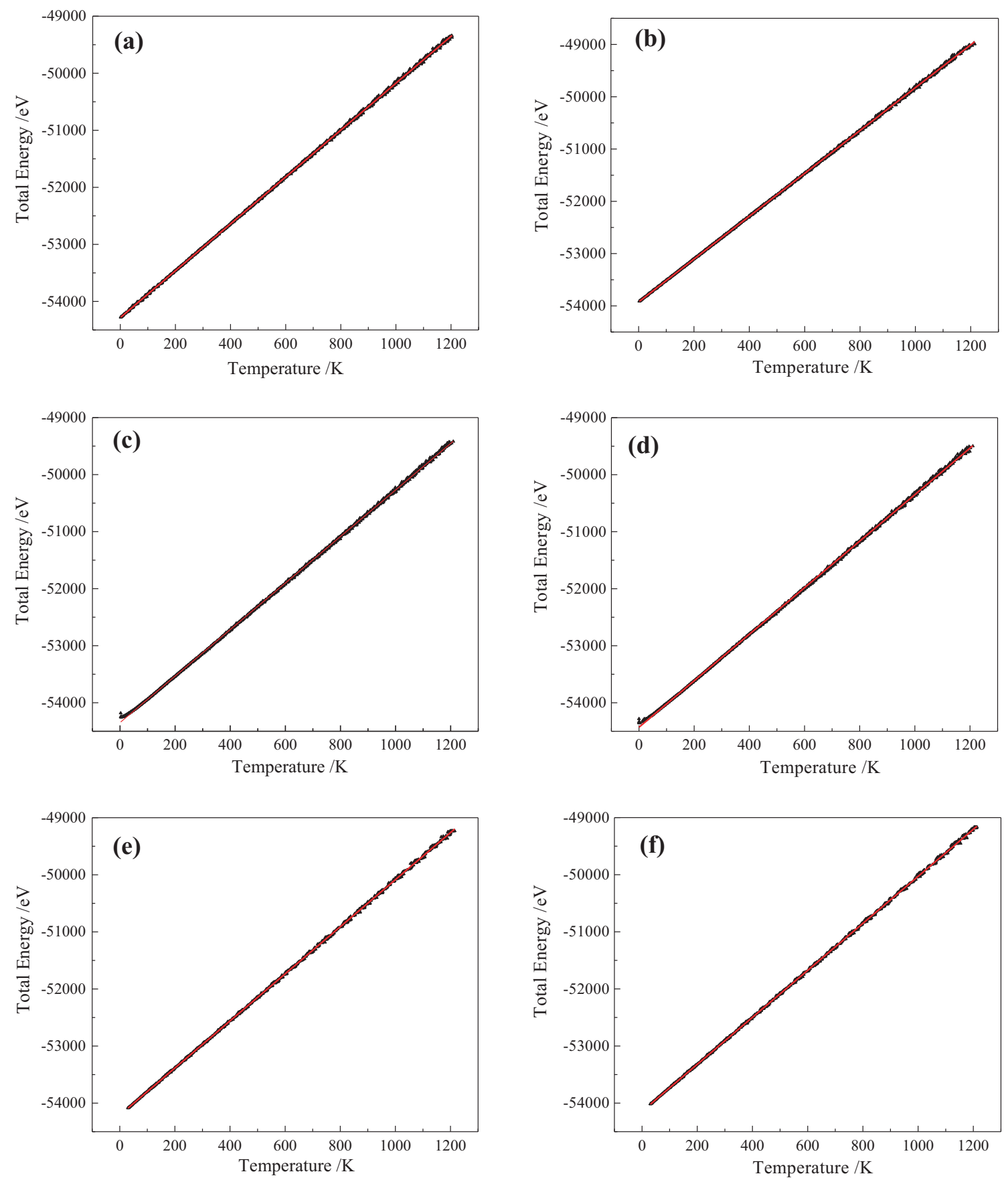

Figure 3. Total energy as a function of temperature for the $\mathrm{Au}-\mathrm{Ag}$ alloy. (a) $\mathrm{Au}-\mathrm{Ag}$ (pure) represents pure $\mathrm{Au}-\mathrm{Ag}$ alloy free of any defect, (b) $\mathrm{Au}-\mathrm{Ag}(\mathrm{V})$ : $\mathrm{Au}-\mathrm{Ag}$ alloy containing vacancy, (c) $\mathrm{Au}-\mathrm{Ag}(\mathrm{Ag})$ : $\mathrm{Au}-\mathrm{Ag}$ alloy containing $\mathrm{Ag}$ interstitial atom, (d) $\mathrm{Au}-\mathrm{Ag}(\mathrm{Au}): \mathrm{Au}-\mathrm{Ag}$ alloy containing $\mathrm{Au}$ interstitial atom, (e) $\mathrm{Au}-\mathrm{Ag}(\mathrm{He}): \mathrm{Au}-\mathrm{Ag}$ alloy containing $\mathrm{He}$ interstitial atom and (f) $\mathrm{Au}-\mathrm{Ag}(\mathrm{He}-\mathrm{V}): \mathrm{Au}-\mathrm{Ag}$ alloy containing $\mathrm{He}-\mathrm{V}$ cluster. Filled triangle and red solid line are calculation data and linear fitting curve, respectively.

state. Next, we evaluate potential energy of every atom in this system, delete the atom with the maximum potential energy, obtain di-vacancy defects, and evaluate the formation energy of di-vacancy, and so on. Vacancy number would gradually increase, and we will obtain a vacancy cluster with different sizes and structures. For the $\mathrm{He}_{n} \mathrm{~V}_{m}$ cluster, we introduce a He atom in the above vacancy cluster, and then, the system is fully relaxed to reach a new energy equilibrium state. Next, 
Table 3. Volumetric heat capacity of the $\mathrm{Au}-\mathrm{Ag}$ alloy.

\begin{tabular}{lcccccc}
\hline Point defect & Pure & $\mathrm{V}$ & $\mathrm{Ag}$ & $\mathrm{Au}$ & $\mathrm{He}$ & $\mathrm{He}-\mathrm{V}$ \\
\hline Volume, $V\left(10^{-24} \mathrm{~cm}^{-3}\right)$ & & \multicolumn{5}{c}{273671.716} \\
$\Delta E / \Delta T\left(\mathrm{eV} \mathrm{K}^{-1}\right)$ & 4.109 & 4.099 & 4.079 & 4.081 & 4.065 & 4.095 \\
Volumetric heat capacity, $C_{\mathrm{V}}\left(\mathrm{J} \mathrm{cm}^{-3} \mathrm{~K}^{-1}\right)$ & 2.406 & 2.400 & 2.388 & 2.389 & 2.380 & 2.397 \\
\hline
\end{tabular}

Pure, V, Ag, Au, He and $\mathrm{He}-\mathrm{V}$ represent pure $\mathrm{Au}-\mathrm{Ag}$ alloy free of any defect, $\mathrm{Au}-\mathrm{Ag}$ alloy containing vacancy, $\mathrm{Au}-\mathrm{Ag}$ alloy containing $\mathrm{Ag}$ interstitial atom, $\mathrm{Au}-\mathrm{Ag}$ alloy containing $\mathrm{Au}$ interstitial atom, $\mathrm{Au}-\mathrm{Ag}$ alloy containing $\mathrm{He}$ interstitial atom and $\mathrm{Au}-\mathrm{Ag}$ alloy containing $\mathrm{He}-\mathrm{V}$ cluster, respectively.

we will obtain an atomic configuration containing $\mathrm{He}_{1} \mathrm{~V}_{m}$ cluster, and evaluate the formation energy of this cluster. Then, we add another He atom into this system, and evaluate the formation energy of the corresponding system. The largest $\mathrm{He}_{n} \mathrm{~V}_{m}$ cluster includes 12 vacancies and seven He atoms in this work, hence, $n / m \leq 7$.

For evaluation of the migration energy for interstitial atom diffusion in the $\mathrm{Au}-\mathrm{Ag}$ alloy, a nudged elastic band (NEB) method is adopted, however, we do not evaluate energy evolution for interstitial diffusion into its neighbouring sites, but migration energy for interstitial atom diffusion into another interstitial site. For this reason, we first evaluate the total energy of interstitial atoms occupying individual interstitial sites. Then, the interstitial site with the minimum energy is viewed as the initial state to diffuse into the transition state with higher energy, and the NEB method is used to evaluate energy evolution during the diffusion procedure. Finally, migration energy for individual interstitial sites is given by equation (4), i.e., deduced from total energy of the saddle point on the minimum energy path (MEP) minus total energy of the initial site $[27,28]$

$$
E_{\mathrm{m}}=E_{\mathrm{s}}-E_{0},
$$

where $E_{\mathrm{m}}$ represents the migration energy of atomic diffusion, $E_{\mathrm{s}}$ the total energy of the interstitial atom located at the saddle point on the MEP and $E_{0}$ the total energy of a system when the interstitial atom locates the initial site. The more the transition states for defect diffusion between initial and final sites one sets, the more precise the saddle point will be. We set 18 transition states for migration energy of defect diffusion in total.

For evaluation of atomic diffusion properties, classical MD simulation might be a direct method, however, it is relatively hard to calculate the diffusion of point defects, possible reasons are listed as follows. Firstly, the jump frequency of point defects in the internal lattice is relatively low, hence, the count number is not enough to satisfy statistical requirements. Secondly, a relatively smaller system size results in number of point defects hardly reaching equilibrium concentration. Thirdly, only longer simulation times could mimic statistically meaningful particle displacement if the number of point defects is smaller, however, the time scale at MD simulation does not satisfy this requirement [8]. For these reasons, introducing excess point defects in a simulation cell might be a feasible way. The atomic jump frequency would be greatly increased when many point defects are introduced into the simulation cell, and create statistical atomic displacement during the simulation procedure. Effective diffusion coefficient $D_{\text {eff }}$ is given by

$$
D_{\text {eff }}=\frac{D_{\text {sim }}}{X_{\mathrm{d}}}
$$

where $D_{\text {sim }}$ is the atomic diffusion coefficient and $X_{\mathrm{d}}$ is the concentration of point defects.

According to the diffusion law of Einstein, $D_{\text {sim }}$ is defined as

$$
D_{\text {sim }}=\lim _{t \rightarrow \infty} \frac{1}{2 N t}\left\langle|r(t)-r(0)|^{2}\right\rangle,
$$

where $r(t)$ represents the atomic coordinate at $t, r(0)$ the initial atomic coordinate and $N$ the dimension of the simulation system. The system in this work is all cubic structure, hence, $N=3$.

Atomic mean square displacement (MSD) is given by

$$
\operatorname{MSD}=\left\langle r^{2}(t)\right\rangle=\frac{1}{n} \sum_{i=1}^{n}\left(\left|r_{i}(t)-r_{i}(0)\right|^{2}\right)
$$

Merging equation (6) with equation (4), one could obtain

$$
D_{\text {sim }}=\frac{\mathrm{MSD}}{6 t} \text {. }
$$

Substituting equation (8) into equation (5), one could obtain an atomic effective diffusion coefficient

$$
D_{\text {eff }}=\frac{\text { MSD }}{6 X_{\mathrm{d}} t} .
$$

During the simulation procedure, we have introduced point defects into the simulation system, and deduced the effective diffusion coefficient from equation (9) through MSD and the concentration of point defects. 

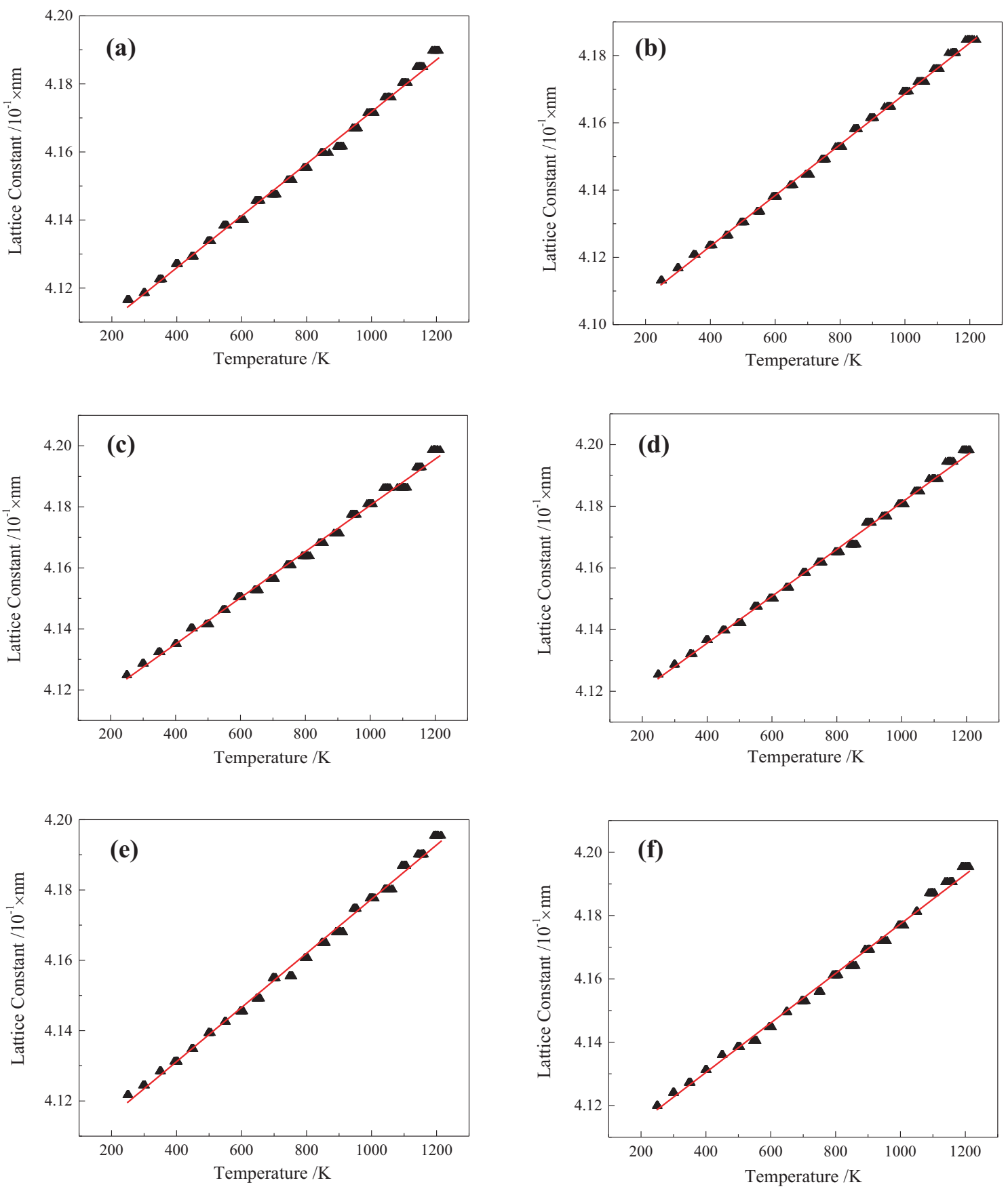

Figure 4. Lattice constant as a function of temperature for the $\mathrm{Au}-\mathrm{Ag}$ alloy. (a) $\mathrm{Au}-\mathrm{Ag}$ (pure) represents pure $\mathrm{Au}-\mathrm{Ag}$ alloy free of any defect, (b) $\mathrm{Au}-\mathrm{Ag}(\mathrm{V})$ : $\mathrm{Au}-\mathrm{Ag}$ alloy containing vacancy, (c) $\mathrm{Au}-\mathrm{Ag}(\mathrm{Ag})$ : $\mathrm{Au}-\mathrm{Ag}$ alloy containing $\mathrm{Ag}$ interstitial atom, (d) $\mathrm{Au}-\mathrm{Ag}(\mathrm{Au}): \mathrm{Au}-\mathrm{Ag}$ alloy containing $\mathrm{Au}$ interstitial atom, (e) $\mathrm{Au}-\mathrm{Ag}(\mathrm{He}): \mathrm{Au}-\mathrm{Ag}$ alloy containing $\mathrm{He}$ interstitial atom and (f) $\mathrm{Au}-\mathrm{Ag}(\mathrm{He}-\mathrm{V})$ : $\mathrm{Au}-\mathrm{Ag}$ alloy containing $\mathrm{He}-\mathrm{V}$ cluster. Filled triangles and red solid line are the calculated data and linear fitting curve, respectively.

For the atomic effective diffusion coefficient in the AuAg alloy, we construct a $20 a_{0} \times 20 a_{0} \times 10 a_{0}$ simulation cell (including 16,000 atoms in total), and introduce point defects, such as vacancy, self-interstitial atom (SIA) and He interstitial atom. For the evaluation of the atomic effective diffusion coefficient, periodic boundary conditions are adopted, and initial atomic velocity obeys Gaussian distribution. Isothermal MD simulation is performed at six different temperatures from 1500 to $2000 \mathrm{~K}$ under the NPT ensemble $(\mathrm{P}=1.0 \mathrm{~atm})$, simulation time at individual temperature is $5.0 \mathrm{~ns}$, then, 
Table 4. Linear expansion coefficient of the $\mathrm{Au}-\mathrm{Ag}$ alloy.

\begin{tabular}{lrrrrrr}
\hline Point defect & Pure & V & Ag & Au & He & He-V \\
\hline Lattice constant $(\AA)$ & & \multicolumn{5}{c}{4.090} \\
$\Delta L / \Delta T\left(10^{-6} \mathrm{~nm} \mathrm{~K}^{-1}\right)$ & 7.637 & 7.748 & 7.774 & 7.807 & 7.878 & 7.812 \\
$\alpha\left(10^{-6} \mathrm{~K}^{-1}\right)$ & 18.672 & 18.943 & 19.007 & 19.088 & 19.262 & 19.100 \\
\hline
\end{tabular}

Pure, $\mathrm{V}, \mathrm{Ag}, \mathrm{Au}, \mathrm{He}$ and $\mathrm{He}-\mathrm{V}$ represent pure $\mathrm{Au}-\mathrm{Ag}$ alloy free of any defect, $\mathrm{Au}-\mathrm{Ag}$ alloy containing vacancy, $\mathrm{Au}-\mathrm{Ag}$ alloy containing $\mathrm{Ag}$ interstitial atom, $\mathrm{Au}-\mathrm{Ag}$ alloy containing $\mathrm{Au}$ interstitial atom, $\mathrm{Au}-\mathrm{Ag}$ alloy containing $\mathrm{He}$ interstitial atom and $\mathrm{Au}-\mathrm{Ag}$ alloy containing $\mathrm{He}-\mathrm{V}$ cluster, respectively.

Table 5. Formation energy (in $\mathrm{eV}$ ) of the interstitial atom in the $\mathrm{Au}-\mathrm{Ag}$ alloy.

\begin{tabular}{lllllll}
\hline $\begin{array}{l}\text { Interstitial } \\
\text { atom }\end{array}$ & $E_{\mathrm{f}}^{\text {Octa1 }}$ & $E_{\mathrm{f}}^{\text {Octa2 }}$ & $E_{\mathrm{f}}^{\text {Octa3 }}$ & $E_{\mathrm{f}}^{\text {Octa4 }}$ & $E_{\mathrm{f}}^{\text {Tetra1 }}$ & $E_{\mathrm{f}}^{\text {Tetra2 }}$ \\
\hline $\mathrm{Au}$ & 3.081 & 2.931 & 2.758 & 2.737 & 3.101 & 3.216 \\
$\mathrm{Ag}$ & 3.129 & 3.088 & 2.894 & 2.885 & 3.261 & 3.295 \\
$\mathrm{He}$ & 3.527 & 3.609 & 4.013 & 3.652 & 3.818 & 4.090 \\
\hline
\end{tabular}

$E_{\mathrm{f}}^{\text {Octai }}(i=1,2,3$ and 4) represents the formation energy of the interstitial atom located at the $i$ th Octa site and $E_{\mathrm{f}}^{\text {Tetra } j}(j=1$ and 2) is the formation energy of the $j$ th Tetra interstitial site.

we record MSD. Finally, we deduce the atomic effective diffusion coefficient through equation (9) and the concentration of point defects.

\section{Influence of point defects on physical properties of Au-Ag alloy}

\subsection{Volumetric heat capacity of $A u-A g$ alloy}

According to volumetric heat capacity defined in equation (10), volume of the simulation system should be fixed when describing total energy as a function of temperature. For this reason, we choose the NVT ensemble for the simulation system, and adopt a Nosé-Hoover thermostat to control the system temperature.

$$
C_{\mathrm{V}}=\frac{\Delta E}{\Delta T \times V},
$$

where $C_{\mathrm{V}}$ is the volumetric heat capacity, $\Delta E$ the variation of total energy, $\Delta T$ the variation of system temperature and $V$ the system volume. System temperature is increased from 2.5 to $1200 \mathrm{~K}$ in a total time of $1200 \mathrm{ps}$, and we determine the temperature and total energy of the simulation system at every $1.0 \mathrm{ps}$. Then, we obtain a slope of $\Delta E / \Delta T$ through linear fitting, and evaluate the volumetric heat capacity of the $\mathrm{Au}-\mathrm{Ag}$ alloy containing various defects.
The $E-T$ curve for the $\mathrm{Au}-\mathrm{Ag}$ alloy is shown in figure 3, and the corresponding volumetric heat capacity is listed in table 3.

The volumetric heat capacity of the $\mathrm{Au}-\mathrm{Ag}$ alloy would decrease, which is arising from various point defects (table 3 ), indicating that endothermic capacity would weaken, which is resulting from point defects. A possible reason is that point defects enhance the activity of host atoms, lattice atoms are more apt to displace from original lattice sites, and accordingly reduce volumetric heat capacity. The reduction amplitude for volumetric heat capacity resulting from the $\mathrm{He}$ interstitial atom would be the largest one since the $\mathrm{He}$ atom is a filled electronic configuration, not readily bonding with host atoms. However, Au and Ag interstitial atoms might bond with host atoms, thus, partial energy would be spent on destroying the bonding behaviours, and endothermic capacity is relatively stronger at higher temperature. As shown in 6th and 7 th columns in table 3, vacancy would combine with the $\mathrm{He}$ atom, form a stable $\mathrm{He}-\mathrm{V}$ cluster, increase volumetric heat capacity and make an $\mathrm{Au}-\mathrm{Ag}$ alloy more stable.

\subsection{Linear expansion coefficient of Au-Ag alloy}

According to equation (11), we choose an NPT ensemble and periodic boundary conditions because the system volume is variable during the evaluation of the linear expansion coefficient in the $\mathrm{Au}-\mathrm{Ag}$ alloy

$$
\beta=\frac{\Delta L}{\Delta T \times L},
$$

where $\beta$ is the linear expansion coefficient, $L$ the lattice constant of the $\mathrm{Au}-\mathrm{Ag}$ alloy and $\Delta L$ the variation for the lattice constant.

For evaluation of the linear expansion coefficient, system temperature is increased from 200 to $1200 \mathrm{~K}$ with a step of $50 \mathrm{~K}$, and total simulation time is $5.0 \mathrm{~ns}$. We determine the system temperature $(T)$ and volume $(V)$ after thermodynamic equilibrium in the NVT ensemble, evaluate lattice constants at different temperatures, plot lattice constant $(L)$ vs. temperature $(T)$ curve, and obtain slope for the $L-T$ curve through linear fitting. Finally, the linear expansion coefficient is deduced from the initial lattice constant and 

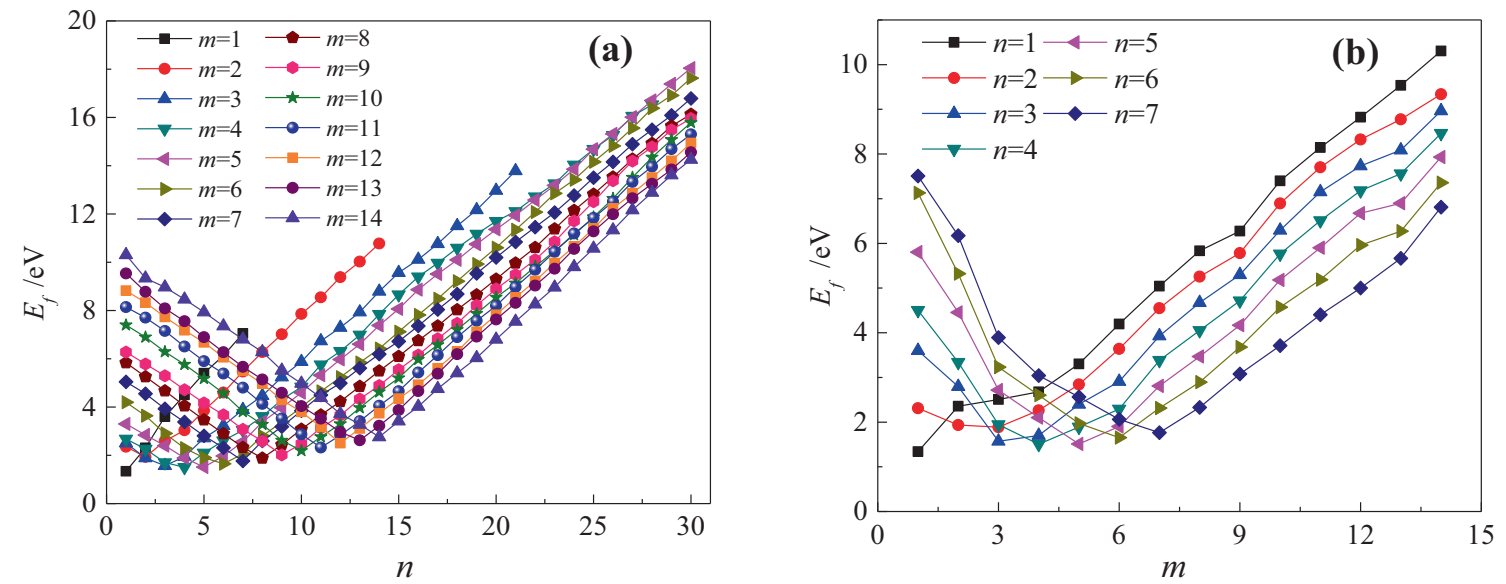

Figure 5. Formation energy of the $\mathrm{He}_{n} \mathrm{~V}_{m}$ cluster as a function of (a) number of vacancies and (b) number of He atoms in the $\mathrm{Au}-\mathrm{Ag}$ alloy. Individual labels for every curve are shown in the legend.
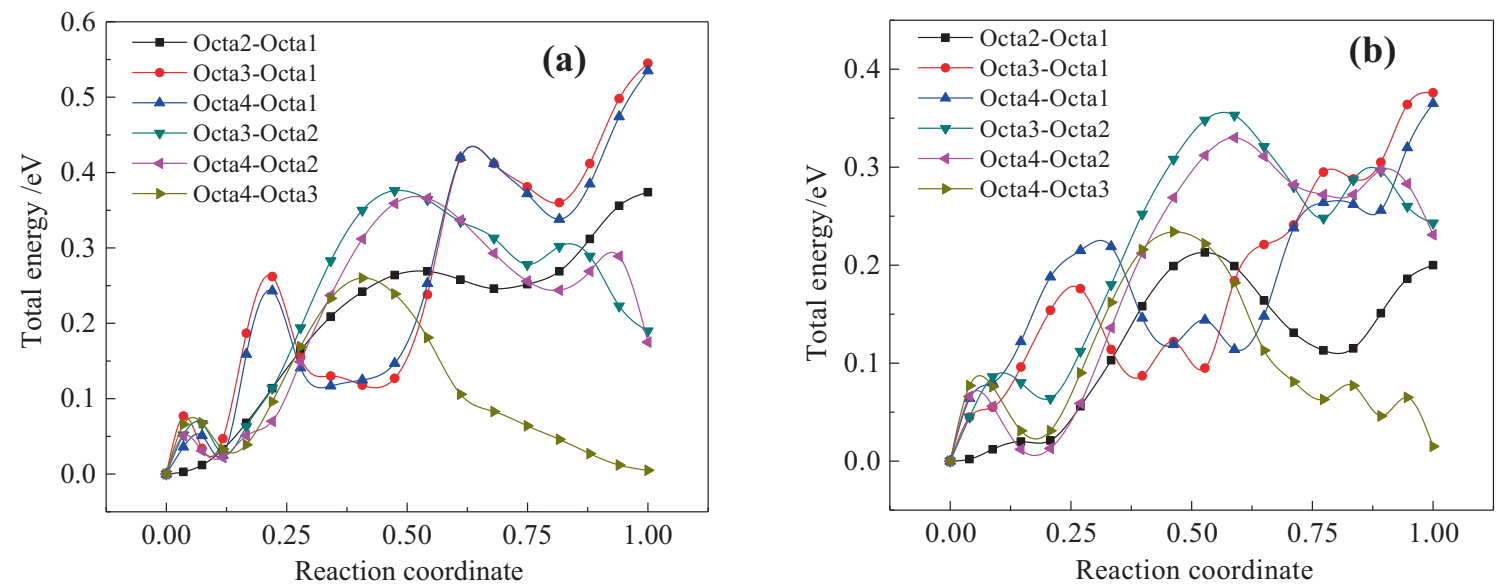

Figure 6. Total energy as a function of reaction coordinate for (a) Au SIA and (b) Ag SIA diffusion between Octa interstitial sites. Individual labels for every curve are shown in the legend.

$\Delta L / \Delta T$. The $L-T$ curve for the $\mathrm{Au}-\mathrm{Ag}$ alloy is shown in figure 4 and the linear expansion coefficient is listed in table 4.

The linear expansion coefficient for the $\mathrm{Au}-\mathrm{Ag}$ alloy would increase due to various point defects (table 4), showing that the introduction of point defects would expand the $\mathrm{Au}-\mathrm{Ag}$ lattice (hence, volume/lattice constant changes), and reduce the structural stability of the Au-Ag alloy. As discussed above, interstitial atoms would collide lattice atoms, produce atomic displacement, and enhance the activity of host atoms. For this reason, structural stability of the Au-Ag alloy would be more susceptible to destroy when the system temperature is increased. Analogy to volumetric heat capacity, the He interstitial atom poses the largest influence on the linear expansion coefficient. A possible reason is that the inertial $\mathrm{He}$ atom is not readily bonded with other atoms, actively collide lattice atom, produce more displaced atoms, and reduce structural stability of the Au-Ag alloys.

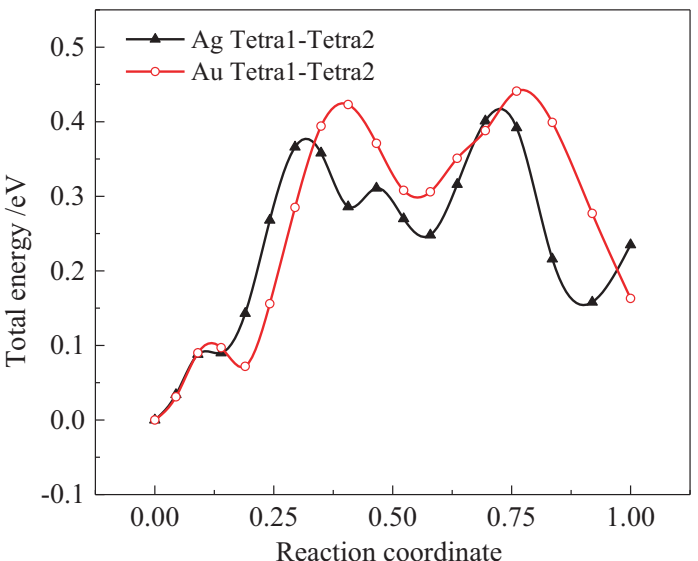

Figure 7. Total energy as a function of reaction coordinate for Tetra interstitial diffusion. Hollow circles and filled triangles represent $\mathrm{Au}$ and Ag SIAs, respectively. 
Table 6. Migration energy, $E_{\mathrm{m}}$ (in eV) of SIA diffusion between various interstitial sites in the $\mathrm{Au}-\mathrm{Ag}$ alloy.

\begin{tabular}{lccccccc}
\hline Interstitial atom & $\mathrm{O}_{2} \rightarrow \mathrm{O}_{1}$ & $\mathrm{O}_{3} \rightarrow \mathrm{O}_{1}$ & $\mathrm{O}_{4} \rightarrow \mathrm{O}_{1}$ & $\mathrm{O}_{3} \rightarrow \mathrm{O}_{2}$ & $\mathrm{O}_{4} \rightarrow \mathrm{O}_{2}$ & $\mathrm{O}_{4} \rightarrow \mathrm{O}_{3}$ & $\mathrm{~T}_{1} \rightarrow \mathrm{T}_{2}$ \\
\hline $\mathrm{Au}$ & 0.269 & 0.545 & 0.537 & 0.376 & 0.351 & 0.260 & 0.441 \\
$\mathrm{Ag}$ & 0.213 & 0.376 & 0.365 & 0.353 & 0.330 & 0.234 & 0.401 \\
\hline
\end{tabular}

$\mathrm{O}_{i}(i=1,2,3$ and 4$)$ represents the $i$ th Octa site and $\mathrm{T}_{j}(j=1$ and 2$)$ is the $j$ th Tetra site.
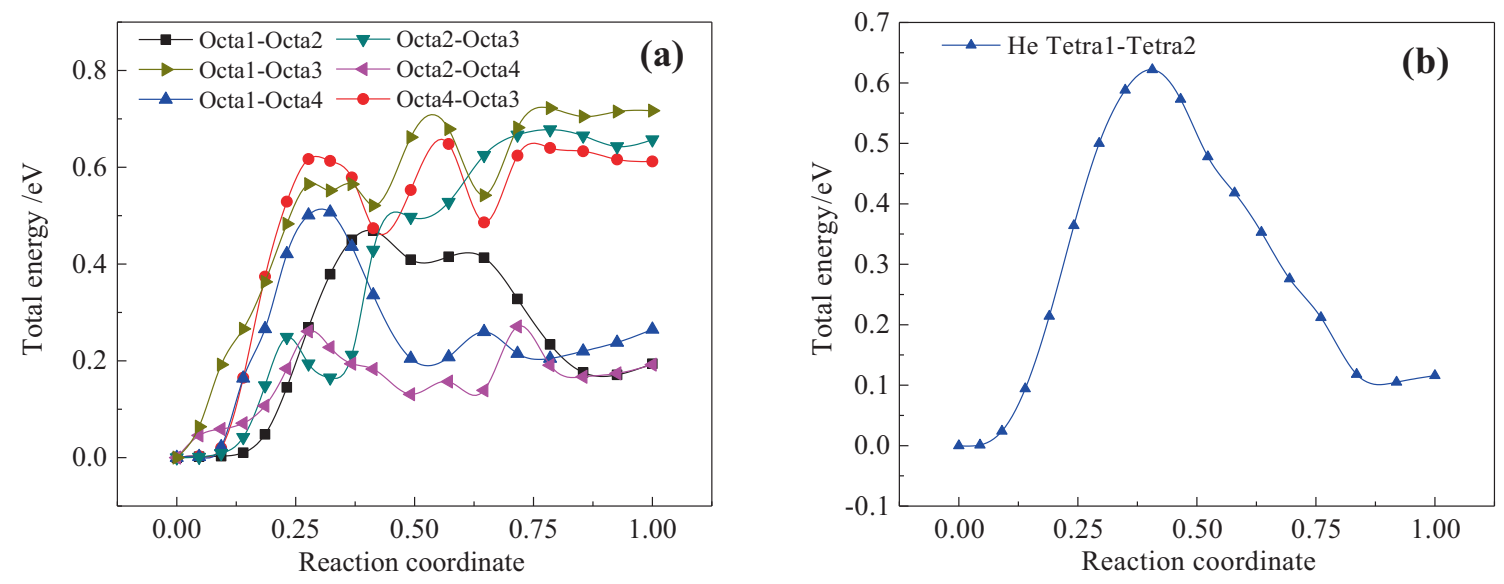

Figure 8. Total energy as a function of reaction coordinate for He diffusion between (a) Octa and (b) Tetra interstitial sites, respectively. Individual labels for every curve are shown in the legend.

\section{Formation energy of point defects}

\subsection{SIA and He atom}

In this subsection, we adopt the MD method to evaluate the total energies of $\mathrm{Au}, \mathrm{Ag}$ SIAs and He occupying interstitial sites after annealing at $0 \mathrm{~K}$, and then, deduce the formation energies of $\mathrm{Au}, \mathrm{Ag}$ and $\mathrm{He}$ located at various interstitial sites in the Au-Ag alloy from equations (12) and (13) as listed in table 5 .

The formation energy of SIA is given by

$$
E_{\mathrm{f}}(\mathrm{SIA})=E_{\mathrm{t}}(16,001 X)-E_{\mathrm{t}}(16,000 X)-E_{\mathrm{t}}(X),
$$

where $X$ represents the host atom ( $\mathrm{Au} / \mathrm{Ag}$ atom in this work). $E_{\mathrm{t}}(X)$ the total energy of a single host atom. $E_{\mathrm{t}}(16,000 X)$ is the total energy of the ideal lattice including 16,000 metallic atoms, while $E_{\mathrm{t}}(16,001 X)$ is the total energy of the above system including a SIA.

As shown in table 5, for $\mathrm{Au}$ and Ag Octa SIAs, formation energy of the Octa4 interstitial site is the smallest, and the sequence of formation energy is $E_{\mathrm{f}}^{\text {Octa1 }}>E_{\mathrm{f}}^{\text {Octa2 }}>$ $E_{\mathrm{f}}^{\mathrm{Octa} 3}>E_{\mathrm{f}}^{\mathrm{Octa} 4}$, indicating that the structure for Octa4 SIA is most stable. However, the formation energy of Octa3 SIA is close to that of Octa4 SIA, namely these two sites have the same structural stability. The formation energy of Octa interstitial defects would decrease with an increase in the first nearest neighbour (1NN) Au atoms in terms of $1 \mathrm{NN}$ for the interstitial site, implying that defect structures of Octa interstitial would increase resulting from an increase in $\mathrm{Au}$ atoms, and enhance structural stability. For the Tetra interstitial site, the formation energy of the Tetra1 interstitial atom is relatively smaller, showing that its structural stability is more stable, namely stability of the defect structure would enhance with a decrease in $1 \mathrm{NN} \mathrm{Au}$ atoms for the interstitial site.

For the Octa defect structure of the He atom in the $\mathrm{Au}-\mathrm{Ag}$ alloy, the formation energy of the Octa1 site is the smallest, indicating that the Octa defect structure of the He atom occupying this site is most stable. The sequence for the formation energy of Octa defect structures is $E_{\mathrm{f}}^{\text {Octa3 }}>E_{\mathrm{f}}^{\text {Octa4 }}>$ $E_{\mathrm{f}}^{\text {Octa2 }}>E_{\mathrm{f}}^{\text {Octa1 }}$, i.e., structural stability of Octa interstitial sites for the He atom obeys Octa1 > Octa2 > Octa4 > Octa3. For the Tetra interstitial defect structure, the formation energy of the Tetral site $(3.818 \mathrm{eV})$ is smaller than that of the Tetra2 site $(4.090 \mathrm{eV})$, implying that the Tetra defect structure for the Tetral site is more stable.

\subsection{He-vacancy cluster}

As mentioned above, the $\mathrm{Pu}$ material would produce $\mathrm{He}$ atom which is insoluble with the material matrix resulting from the spontaneous $\alpha$ decay during long-term storage, and these He atoms are readily combining with vacancy $(\mathrm{V})$ to form 
Table 7. Migration energy $E_{\mathrm{m}}(\mathrm{in} \mathrm{eV}$ ) of $\mathrm{He}$ atom diffused between various interstitial sites in the $\mathrm{Au}-\mathrm{Ag}$ alloy.

\begin{tabular}{lccccccc}
\hline Interstitial atom & $\mathrm{O}_{1} \rightarrow \mathrm{O}_{2}$ & $\mathrm{O}_{1} \rightarrow \mathrm{O}_{3}$ & $\mathrm{O}_{1} \rightarrow \mathrm{O}_{4}$ & $\mathrm{O}_{2} \rightarrow \mathrm{O}_{3}$ & $\mathrm{O}_{2} \rightarrow \mathrm{O}_{4}$ & $\mathrm{O}_{4} \rightarrow \mathrm{O}_{3}$ & $\mathrm{~T}_{1} \rightarrow \mathrm{T}_{2}$ \\
\hline $\mathrm{He}$ & 0.469 & 0.722 & 0.507 & 0.678 & 0.271 & 0.648 & 0.622 \\
\hline
\end{tabular}

$\mathrm{O}_{i}(i=1,2,3$ and 4$)$ represents the $i$ th Octa site and $\mathrm{T}_{j}(j=1$ and 2$)$ is the $j$ th Tetra site.
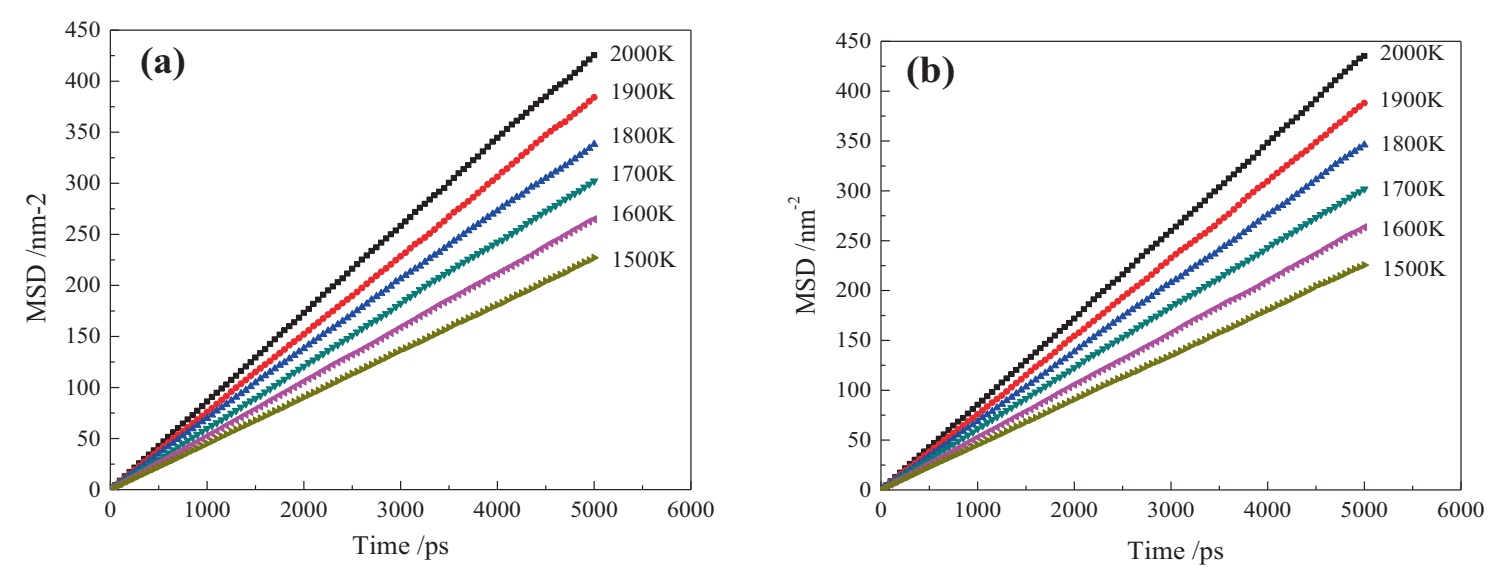

Figure 9. MSD as a function of simulation time for the Ag atom in the Au-Ag alloy containing (a) Ag SIA and (b) Au SIA. Individual labels for every curve are shown in the legend.

Table 8. Diffusion coefficient for $\mathrm{Ag}$ atom in the $\mathrm{Au}-\mathrm{Ag}$ alloy.

\begin{tabular}{llllllll}
\hline Simulation system & Diffusion coefficient & $1500 \mathrm{~K}$ & $1600 \mathrm{~K}$ & $1700 \mathrm{~K}$ & $1800 \mathrm{~K}$ & $1900 \mathrm{~K}$ & $2000 \mathrm{~K}$ \\
\hline $\mathrm{Au}-\mathrm{Ag}(\mathrm{Au})$ & $D_{\text {sim }}^{\mathrm{Ag}}\left(10^{-2} \mathrm{~nm}^{2} \mathrm{ps}^{-1}\right)$ & 0.7511 & 0.8772 & 1.009 & 1.152 & 1.295 & 1.455 \\
& $D_{\text {eff }}^{\mathrm{Ag}}\left(\mathrm{nm}^{2} \mathrm{ps}^{-1}\right)$ & 1.5023 & 1.7544 & 2.018 & 2.305 & 2.589 & 2.91 \\
$\mathrm{Au}-\mathrm{Ag}(\mathrm{Ag})$ & $D_{\text {sim }}^{\mathrm{Ag}}\left(10^{-2} \mathrm{~nm}^{2} \mathrm{ps}^{-1}\right)$ & 0.756 & 0.8843 & 1.016 & 1.125 & 1.279 & 1.425 \\
& $D_{\text {eff }}^{\mathrm{Ag}}\left(\mathrm{nm}^{2} \mathrm{ps}^{-1}\right)$ & 1.512 & 1.7686 & 2.026 & 2.25 & 2.557 & 2.85 \\
\hline
\end{tabular}

$\mathrm{Au}-\mathrm{Ag}(\mathrm{Au})$ and $\mathrm{Au}-\mathrm{Ag}(\mathrm{Ag})$ represent $\mathrm{Au}-\mathrm{Ag}$ alloy containing $\mathrm{Au}$ SIA and $\mathrm{Ag}$ SIA, respectively. $D_{\text {sim }}^{\mathrm{Ag}}$ and $D_{\text {eff }}^{\mathrm{Ag}}$ are simulated and effective diffusion coefficients for $\mathrm{Ag}$ atom in the $\mathrm{Au}-\mathrm{Ag}$ alloy, respectively.

a $\mathrm{He}_{n} \mathrm{~V}_{m}$ cluster, of which formation energy is useful for understanding the He behaviour in the material. We evaluate the formation energy of the $\mathrm{He}_{n} \mathrm{~V}_{m}$ cluster in an alternate candidate for the $\mathrm{Pu}-\mathrm{Ga}$ alloy, i.e., $\mathrm{Au}-\mathrm{Ag}$ alloy, as shown in figure $5 \mathrm{a}$ and $\mathrm{b}(n>30$, not shown here).

As shown in figure $5 \mathrm{a}$, the formation energy of the $\mathrm{He}_{n} \mathrm{~V}_{m}$ cluster gradually decreases with an increase in vacancy when the number of $\mathrm{He}$ atoms is fixed, and the formation energy reaches the minimum value if number of $\mathrm{He}$ atoms is equal to that of vacancies, i.e., $n=m$. The formation energy of the $\mathrm{He}_{n} \mathrm{~V}_{m}$ cluster gradually increases with a further increase in $\mathrm{He}$ atoms, indicating that the $\mathrm{He}_{n} \mathrm{~V}_{m}$ cluster is most stable at $n=m$. One may draw the same conclusion from the formation energy of the $\mathrm{He}_{n} \mathrm{~V}_{m}$ cluster as a function of $\mathrm{He}$ atom $n$ (figure $5 \mathrm{~b}$ ), namely formation energy would first decrease and then increase with an increase in the He atoms when the number of vacancies is kept constant. The formation energy would reach the minimum value at $n=m$. One could see from figure $5 \mathrm{a}$ and $\mathrm{b}$ that the structure of the $\mathrm{He}_{n} \mathrm{~V}_{m}$ cluster is most stable when one vacancy is occupied by one He atom in the $\mathrm{Au}-\mathrm{Ag}$ alloy.

\section{Migration energy of point defects}

\subsection{Migration energy of SIA}

As discussed above, we have evaluated formation energies for various interstitial sites, and find that structural stability 

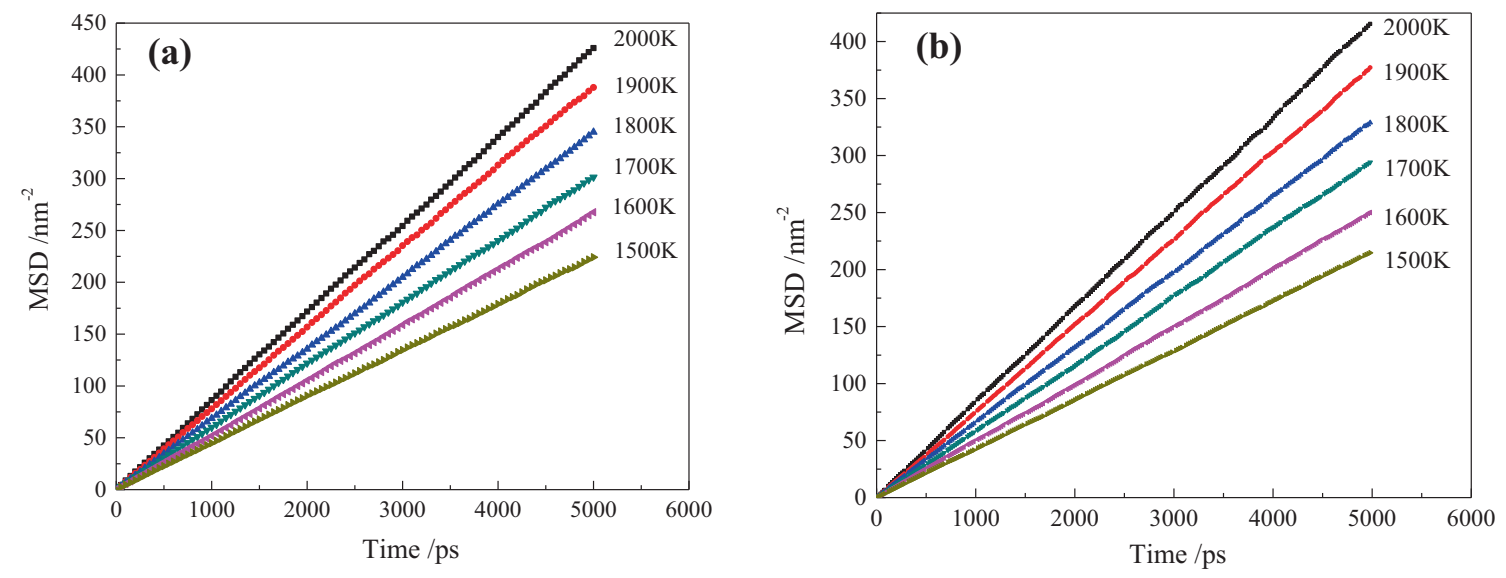

Figure 10. MSD for Ag atom in the Au-Ag alloy containing (a) vacancy and (b) He atom. Individual labels for every curve are shown in the legend.

for Octa interstitial defects obeys Octa $1<$ Octa $2<$ Octa3 $<$ Octa4, while for Tetra interstitial defect Tetra $<$ Tetra1. Then, we choose a relatively stable defect structure for SIA in the $\mathrm{Au}-\mathrm{Ag}$ alloy as an initial diffusion state, while another relative unstable defect structure as a final state, and describe evolution of total energy between initial and final states using the NEB method. The results for Octa and Tetra SIA diffusion are shown in figures 6 and 7, respectively. Migration energy $E_{\mathrm{m}}$ deduced from equation (4) is listed in table 6.

As shown in table 6, migration energy for Au SIA diffusion from Octa4 to Octa3 is the smallest case, indicating that SIA located at the Octa4 site is the most apt to diffuse into the Octa3 site. However, Au SIA located at the Octa3 site tends to diffuse into the Octa 2 site. These observations establish that Au SIA would diffuse between Octa interstitial sites with similar structural stability. Note, however, that migration energy of $\mathrm{Ag}$ is smaller than that of the $\mathrm{Au}$ atom at the same diffusion sites, indicating that $\mathrm{Ag}$ SIA is more apt to diffuse into other interstitial sites as compared to Au SIA. Octa $4 \rightarrow$ Octa 2 and Octa $4 \rightarrow$ Octa1 diffusion paths are similar to Octa3 $\rightarrow$ Octa2 and Octa3 $\rightarrow$ Octa1 (figure 7), respectively. For Octa $4 \rightarrow$ Octa3 diffusion, total energy for the initial state is close to its final state, implying that total energy of the defect structure for Octa4 SIA is close to that of Octa3 site, which is consistent with formation energies for $E_{\mathrm{f}}^{\mathrm{Octa} 3}$ and $E_{\mathrm{f}}^{\mathrm{Octa} 4}$.

\subsection{Migration energy for He atom}

In section 4, we have evaluated the formation energies for Octa and Tetra He interstitial atoms. In this section, we will evaluate migration energy for He diffusion from a relatively stable interstitial site to a relatively stable interstitial site using the NEB method, and total energy as a function of reaction coordinate for different He interstitial sites is shown in figure $8 \mathrm{a}$ and $\mathrm{b}$. Migration energy $E_{\mathrm{m}}$ deduced from equation (1) is listed in table 7.
As shown in figure $8 \mathrm{a}$, Octa $1 \rightarrow$ Octa3, Octa $2 \rightarrow$ Octa3 and Octa $4 \rightarrow$ Octa3 diffusion paths are similar, indicating that total energies and spatial arrangements for He Octa1, Octa2 and Octa4 interstitial sites are also similar. The formation energy of $\mathrm{He}$ Octa3 sites is remarkably larger than those of the other three interstitial sites (table 7), and formation energies of Octa1, Octa2 and Octa4 are close to each other, which verify the above conclusion. In addition, migration energies for Octa $1 \rightarrow$ Octa3, Octa2 $\rightarrow$ Octa3 and Octa $4 \rightarrow$ Octa3 paths are larger than those of other diffusion paths, and total energy of the Octa3 site is obviously larger than those of the other sites, also verifying the above conclusion.

\section{Calculation of effective diffusion coefficient}

\section{$6.1 \quad$ SIA}

To further understand the SIA behaviour in the $\mathrm{Au}-\mathrm{Ag}$ alloy, we evaluate the effective diffusion coefficient of the Ag atom for the $\mathrm{Au}-\mathrm{Ag}$ alloy containing 0.5 at.\% SIA. For evaluation of the atomic effective diffusion coefficient, $80 \mathrm{Au}$ and 80 $\mathrm{Ag}$ atoms are introduced into the $\mathrm{Au}-\mathrm{Ag}$ alloy, respectively. Periodic boundary conditions and NPT ensemble are adopted. Isothermal MD simulation (total simulation time is $5.0 \mathrm{~ns}$ ) is performed at six different temperatures from 1500 to $2000 \mathrm{~K}$, and then, we record Ag MSD in the Au-Ag alloy as shown in figure $9 \mathrm{a}$ and $\mathrm{b}$. Next, we linearly fit the MSD curve, and obtain a slope of MSD vs. $t$ curve. Finally, we deduced simulated and effective diffusion coefficients for the $\mathrm{Ag}$ atom in the $\mathrm{Au}-\mathrm{Ag}$ alloy containing $\mathrm{Au} / \mathrm{Ag}$ SIAs through equation (12) in table 8.

As shown in table 8, the effective diffusion coefficient for the $\mathrm{Ag}$ atom in the $\mathrm{Au}-\mathrm{Ag}$ alloy would enhance with an increase in temperature, no matter whether the introduction of the $\mathrm{Au}$ or $\mathrm{Ag}$ atom. A possible reason is that, as we all know, temperature will increase the average kinetic energy when the 
Table 9. Diffusion coefficient for $\mathrm{Ag}$ atom in the $\mathrm{Au}-\mathrm{Ag}$ alloy containing vacancy and $\mathrm{He}$ atom.

\begin{tabular}{llllllll}
\hline System & Diffusion coefficient & $1500 \mathrm{~K}$ & $1600 \mathrm{~K}$ & $1700 \mathrm{~K}$ & $1800 \mathrm{~K}$ & $1900 \mathrm{~K}$ & $2000 \mathrm{~K}$ \\
\hline $\mathrm{Au}-\mathrm{Ag}(\mathrm{V})$ & $D_{\text {sim }}^{\mathrm{Ag}}\left(10^{-2} \mathrm{~nm}^{2} \mathrm{ps}^{-1}\right)$ & 0.7453 & 0.8893 & 1.003 & 1.147 & 1.299 & 1.413 \\
& $D_{\mathrm{eff}}^{\mathrm{Ag}}\left(\mathrm{nm}^{2} \mathrm{ps}^{-1}\right)$ & 1.491 & 1.777 & 2.006 & 2.294 & 2.598 & 2.826 \\
$\mathrm{Au}-\mathrm{Ag}(\mathrm{He})$ & $D_{\text {sim }}^{\mathrm{Ag}}\left(10^{-2} \mathrm{~nm}^{2} \mathrm{ps}^{-1}\right)$ & 0.7198 & 0.8363 & 0.988 & 1.1003 & 1.2635 & 1.389 \\
& $D_{\mathrm{eff}}^{\mathrm{Ag}}\left(\mathrm{nm}^{2} \mathrm{ps}^{-1}\right)$ & 1.4396 & 1.6726 & 1.976 & 2.2006 & 2.527 & 2.779 \\
\hline
\end{tabular}

$\mathrm{Au}-\mathrm{Ag}(\mathrm{V})$ and $\mathrm{Au}-\mathrm{Ag}(\mathrm{He})$ represent $\mathrm{Au}-\mathrm{Ag}$ alloy containing vacancy and $\mathrm{He}$ atom, respectively.

$D_{\text {sim }}^{\mathrm{Ag}}$ and $D_{\text {eff }}^{\mathrm{Ag}}$ are simulated and effective diffusion coefficients for $\mathrm{Ag}$ atom in the $\mathrm{Au}-\mathrm{Ag}$ alloy, respectively.
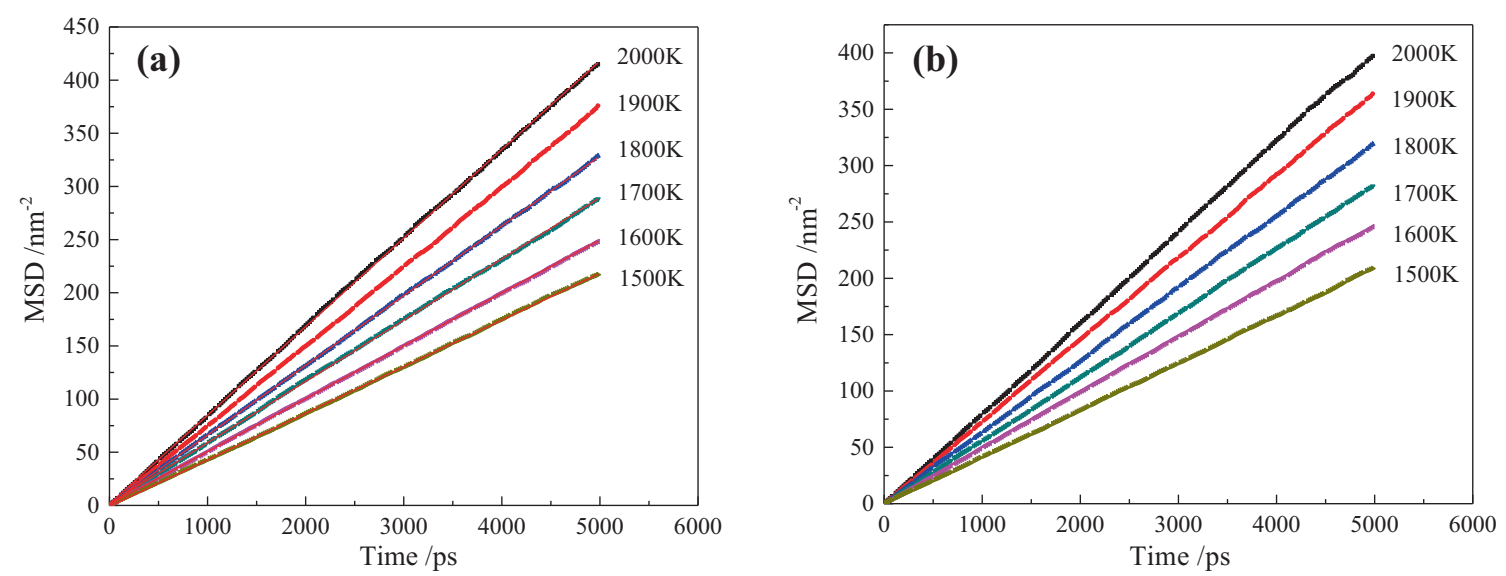

Figure 11. MSD as a function of simulation time for (a) Ag and (b) Au in the Au-Ag alloy containing He-V cluster. Individual labels for every curve are shown in the legend.

interatomic interaction is fixed. For this reason, it is expected that diffusion, being an activated process, of which effective diffusion coefficient will increase with temperature. Therefore, the $\mathrm{Ag}$ atom would move faster, and MSD and effective diffusion coefficients for the Ag atom would be larger. However, the effective diffusion coefficient for the $\mathrm{Ag}$ atom in the $\mathrm{Au}-\mathrm{Ag}$ alloy containing Au SIA would be larger at the same temperature because $\mathrm{Au}$ is higher in atomic number and electron number. An interaction between $\mathrm{Au}$ and $\mathrm{Au} / \mathrm{Ag}$ atoms is obviously higher than those of $\mathrm{Ag}$ atoms; the introduction of the $\mathrm{Au}$ atom would activate lattice atoms and enhance atomic diffusion.

\subsection{Vacancy and He atom}

For migration energies of vacancy and He atoms, 80 vacancies and $\mathrm{He}$ atoms are introduced into the $\mathrm{Au}-\mathrm{Ag}$ alloy, respectively. Isothermal MD simulation (total simulation time is $5.0 \mathrm{~ns}$ ) is performed at six different temperatures from 1500 to $2000 \mathrm{~K}$, and then, we record Ag MSD in the Au-Ag alloy as shown in figure 10. Next, we linearly fit the MSD curve, and obtain a slope of MSD vs. $t$ curve. Finally, we deduce simulated and effective diffusion coefficients for vacancy and the $\mathrm{He}$ atom in the $\mathrm{Au}-\mathrm{Ag}$ alloy through equation (12) in table 9.
As shown in table 9, temperature rise would enhance atomic diffusion in the $\mathrm{Au}-\mathrm{Ag}$ alloy. Compared to the effective diffusion coefficient for the $\mathrm{Ag}$ atom in the $\mathrm{Au}-\mathrm{Ag}$ alloy containing vacancy and $\mathrm{He}$ atom at the same temperature, one could see that the $\mathrm{He}$ atom is not readily bonding with the $\mathrm{Au}$ and/or $\mathrm{Ag}$ atom due to its filled shell electron configuration, and has a strong repulsion with the matrix atom, resulting in a decrease of atomic diffusion. However, vacancy is more apt to combine with the matrix atom, and makes atom readily diffusion into vacancy defects. Therefore, the $\mathrm{He}$ atom has a stronger suppression on diffusion in the $\mathrm{Au}-\mathrm{Ag}$ alloy.

\subsection{He-vacancy cluster}

For the effect of the He-V cluster on atomic diffusion in the $\mathrm{Au}-\mathrm{Ag}$ alloy, we construct a $20 a_{0} \times 20 a_{0} \times 10 a_{0}$ simulation cell $\left(16,000\right.$ atoms), and introduce a $\mathrm{He}_{80} \mathrm{~V}_{16}$ cluster composed of $80 \mathrm{He}$ atoms and 16 vacancies. For the evaluation of the atomic diffusion coefficient, periodic boundary conditions are adopted, and initial atomic velocity obeys Gaussian distribution. To analyse the influence of temperature on atomic diffusion, isothermal MD simulation is performed at six different temperatures from 1500 to $2000 \mathrm{~K}$ under the NPT ensemble, and then we record Ag MSD in the Au$\mathrm{Ag}$ alloy as shown in figure 11a and b. Next, we linearly 
Table 10. Diffusion coefficient for $\mathrm{Ag} / \mathrm{Au}$ atom in the $\mathrm{Au}-\mathrm{Ag}$ alloy containing $\mathrm{He}-\mathrm{V}$ cluster.

\begin{tabular}{llllllll}
\hline System & Diffusion coefficient & $1500 \mathrm{~K}$ & $1600 \mathrm{~K}$ & $1700 \mathrm{~K}$ & $1800 \mathrm{~K}$ & $1900 \mathrm{~K}$ & $2000 \mathrm{~K}$ \\
\hline $\mathrm{Au}-\mathrm{Ag}(\mathrm{He}-\mathrm{V})$ & $D_{\text {sim }}^{\mathrm{Ag}}\left(10^{-2} \mathrm{~nm}^{2} \mathrm{ps}^{-1}\right)$ & 0.7311 & 0.8291 & 0.9603 & 1.093 & 1.249 & 1.388 \\
& $D_{\text {eff }}^{\mathrm{Ag}}\left(\mathrm{nm}^{2} \mathrm{ps}^{-1}\right)$ & 1.4622 & 1.6582 & 1.9206 & 2.186 & 2.498 & 2.776 \\
& $D_{\text {sim }}^{\mathrm{Au}}\left(10^{-2} \mathrm{~nm}^{2} \mathrm{ps}^{-1}\right)$ & 0.6971 & 0.8243 & 0.9466 & 1.067 & 1.2165 & 1.3435 \\
& $D_{\text {eff }}^{\mathrm{Au}}\left(\mathrm{nm}^{2} \mathrm{ps}^{-1}\right)$ & 1.3942 & 1.6486 & 1.8932 & 2.134 & 2.433 & 2.687 \\
\hline
\end{tabular}

$D_{\text {sim }}^{\mathrm{Ag}}\left(D_{\text {sim }}^{\mathrm{Au}}\right)$ and $D_{\text {eff }}^{\mathrm{Ag}}\left(D_{\text {eff }}^{\mathrm{Au}}\right)$ are simulated and effective diffusion coefficients for $\mathrm{Ag}(\mathrm{Au})$ atom in the $\mathrm{Au}-\mathrm{Ag}$ alloy, respectively.

fit the MSD curve, and obtain a slope of MSD vs. $t$ curve. Finally, we deduce simulated and effective diffusion coefficients for the $\mathrm{Ag} / \mathrm{Au}$ atom in the $\mathrm{Au}-\mathrm{Ag}$ alloy containing a $\mathrm{He}_{80} \mathrm{~V}_{16}$ cluster through equation (12) and are listed in table 10 .

As shown in table 10, temperature rise would enhance atomic diffusion in the $\mathrm{Au}-\mathrm{Ag}$ alloy, and the effective diffusion coefficient for the $\mathrm{Ag}$ atom is somewhat larger than that of the $\mathrm{Au}$ atom at the same temperature, the $\mathrm{Ag}$ atom moves faster, and is more apt to diffuse. A possible reason is that the diffusion velocity of $\mathrm{Ag}$ is slower than that of the $\mathrm{Au}$ atom due to the atomic weight of Au being larger. Compared to the diffusion coefficient of the $\mathrm{Ag}$ atom in the $\mathrm{Au}-\mathrm{Ag}$ alloy containing $\mathrm{He}$ atom in table 8 , the diffusion coefficient of the $\mathrm{He}-\mathrm{V}$ cluster is relatively smaller, indicating that the introduction of vacancy defects would further decrease atomic diffusion, vacancy is readily combined with the $\mathrm{He}$ atom to form a stable $\mathrm{He}-\mathrm{V}$ cluster, enhance structural stability of the $\mathrm{Au}-\mathrm{Ag}$ alloy, and hinder atomic diffusion, namely the $\mathrm{He}-\mathrm{V}$ cluster has a remarkable inhibition on atomic diffusion.

\section{Summary and outlook}

In this work, we have evaluated energetics and diffusion properties of the $\mathrm{Au}-\mathrm{Ag}$ alloy containing various point defects using a MD method, in particular, formation energy for point defects, migration energy for point defects diffusion into interstitial sites, and diffusion coefficient for the Au-Ag alloy containing point defects, such as vacancy, He atom and He$\mathrm{V}$ cluster. The results show that a melting point, volumetric heat capacity and linear expansion coefficient would decrease resulting from the introduction of various point defects, $\mathrm{He}$ atom has the most remarkable influence on the physical properties of the $\mathrm{Au}-\mathrm{Ag}$ alloy for various point defects considering in this work. For the $\mathrm{He}_{n} \mathrm{~V}_{m}$ cluster, the formation energy of the defect structure is most stable at $n=m$. SIA is more apt to diffuse between two Octa interstitial sites with similar structural stability. The diffusion coefficient of the He-V cluster is relatively smaller, indicating that the introduction of vacancy defects would further decrease atomic diffusion, vacancy is readily combining with He atom to form a stable
He- $\mathrm{V}$ cluster, enhance structural stability of the Au-Ag alloy and hinder atomic diffusion. The influence of various point defects on diffusion velocity in the Au-Ag alloy obeys $\mathrm{He}-\mathrm{V}$ cluster $>\mathrm{He}>$ vacancy $>\mathrm{Ag}>\mathrm{Au}$. This work could be viewed as an analogous work to investigate point defects in the $\mathrm{Pu}-\mathrm{Ga}$ alloy, in particular, nucleation and growth mechanism for He bubbles in aging the $\mathrm{Pu}-\mathrm{Ga}$ alloy. In future works, we plan to adopt the MD method and/or the mesoscopic technique to simulate the properties of point defects, such as SIA, $\mathrm{He}-\mathrm{V}$ cluster and $\mathrm{He}$ bubbles in $\mathrm{Pu}-\mathrm{Ga}$ alloys, and compare the theoretical result with available experimental data, such as TEM, SEM and PAS examination of He-implanted and/or aging samples.

\section{Acknowledgements}

This work is supported by the National Science Foundation of China under contract nos. 51401237, 11474358 and 51271198; the Scientific Research Program Funded by Shaanxi Provincial Education Department (program no. 18JK1207); and the Defence Technology Foundation of China under contract no. 2301003.

\section{References}

[1] Baskes M L 2000 Phys. Rev. B 6215532

[2] Pochet P 2003 Nucl. Instrum. Meth. B 20282

[3] Ao B Y, Wang X L, Hu W Y, Yang J Y and Xia J X 2007 J. Alloys Compd. 444-445 300

[4] Ao B Y, Chen P H, Shi P and Wang X L 2012 Commun. Comput. Phys. 111205

[5] Robinson M, Kenny S D, Smith R and Storr M T 2012 J. Nucl. Mater. $\mathbf{4 2 3} 16$

[6] Scott C, Kenny S D, Storr M T and Willetts A 2013 J. Nucl. Mater. $\mathbf{4 4 2} 83$

[7] Robinson M, Kenny S D, Smith R and Storr M T 2014 J. Nucl. Mater. 444493

[8] Wu F C, Wang P, Liu X Y and Wu H A 2017 J. Nucl. Mater. 4847

[9] Karavaev A V, Dremov V V and Ionov G V 2017 J. Nucl. Mater. 49685 
[10] Valone S M, Baskes M L, Stan M, Mitchell T E, Lawson A C and Sickafus K E 2004 J. Nucl. Mater. 32441

[11] Savrasov S Y, Kotliar G and Abrahams E 2001 Nature (London) 410793

[12] Dai X, Savrasov S Y, Kotliar G, Migliori A, Ledbetter H and Abrahams E 2003 Science 300953

[13] Moore K T, Söderlind P, Schwartz A J and Laughlin D E 2006 Phys. Rev. Lett. 96206402

[14] Petit L, Svane A, Szotek Z and Temmerman W M 2003 Science 301498

[15] Stevens M F, Zocco T, Albers R, Becker J D, Walter K, Cort B et al 1998 Fundamental and applied studies of helium ingrowth and aging in plutonium (United States: Los Alamos National Laboratory) https://doi.org/10.2172/296814

[16] Thomé T and Grynszpan R I 2006 Radiat. Eff. Defect. S. 161 347

[17] Zhu Z Q 2013 MS thesis (Chengdu: University of Electronic Technology) (in Chinese)

[18] Zu X T, Yang L, Gao F, Peng S M, Heinisch H L, Long X G et al 2009 Phys. Rev. B $\mathbf{8 0} 054104$
[19] Zhou X W, Wadley H N G, Johnson R A, Larson D J, Tabat N, Cerezo A et al 2006 Acta Mater. 494005

[20] Zhou X W, Wadley H N G, Filho J S and Neurock M N 2004 Phys. Rev. B 69035402

[21] Valone S M, Baskes M I and Martin R L 2006 Phys. Rev. B 73 214209

[22] Rose J H, Smith J R, Guinea F and Ferrante J 1984 Phys. Rev. B 292963

[23] Schwarz K, Blaha P and Madsen G K H 2002 Commun. Comput. Phys. 14771

[24] Schwarz K 2003 J. Solid State Chem. 176319

[25] Schwarz K, Blaha P and Trickey S B 2010 Mol. Phys. 108 3147

[26] Perdew J P, Burke K and Ernzerhof M 1996 Phys. Rev. Lett. 77 38065

[27] Zhang J M, Song X L, Zhang X J and Xu K W 2006 J. Phys. Chem. Solids 67714

[28] Zhang B W, Hu W Y and Shu X L 2005 Theory of embedded atom method and its application to material science (Changsha: Hu'nan University Press) p 84 